

\title{
Optomechanical coupling in a quartz crystal resonator for cryogenic clocks
}

Jérémy Bon, Kevin Rosenziveig, Philippe Abbé, Cyrus Rocher, Serge Galliou, Leonhard Neuhaus, Samuel Deléglise, Tristan Briant, Pierre Cohadon

\section{- To cite this version:}

Jérémy Bon, Kevin Rosenziveig, Philippe Abbé, Cyrus Rocher, Serge Galliou, et al.. Optomechanical coupling in a quartz crystal resonator for cryogenic clocks. International Frequency Control Symposium, May 2018, Olympic Valley, CA, United States. hal-02472708

\section{HAL Id: hal-02472708 \\ https://hal.science/hal-02472708}

Submitted on 10 Feb 2020

HAL is a multi-disciplinary open access archive for the deposit and dissemination of scientific research documents, whether they are published or not. The documents may come from teaching and research institutions in France or abroad, or from public or private research centers.
L'archive ouverte pluridisciplinaire HAL, est destinée au dépôt et à la diffusion de documents scientifiques de niveau recherche, publiés ou non, émanant des établissements d'enseignement et de recherche français ou étrangers, des laboratoires publics ou privés. 


\section{Optomechanical coupling in a quartz crystal resonator for cryogenic clocks}

\author{
J. Bon, K. Rosenziveig, Ph. Abbé, C. Rocher, \\ S. Galliou \\ FEMTO-ST Institute, Univ. Bourgogne Franche-Comté, \\ CNRS \\ ENSMM, 25000 Besançon, France. \\ serge.galliou@femto-st.fr
}

\author{
L. Neuhaus, S. Deléglise,T. Briant, P.-F. Cohadon \\ Laboratoire Kastler Brossel, UPMC-Sorbonne Universités, \\ CNRS, \\ ENS-PSL Research University, Collège de France \\ 75005 Paris, France \\ cohadon@lkb.upmc.fr
}

\begin{abstract}
Plano-convex quartz crystal resonators can exhibit quality-factors close to a billion at $4 \mathrm{~K}$. They are also suitable to operate as optical cavities. As a consequence they are good candidates for optomechanic experiments including quartz-based cryogenic clocks. The paper is focused on the latter application and demonstrates its feasability.
\end{abstract}

Keywords-Optomechanics, Low Mechanical Loss, Quartz Resonator, Optical Cavity, Acoustic Cavity.

\section{INTRODUCTION}

Devices under consideration in this paper are mainly bulk acoustic wave (BAW) resonators made in quartz crystal SC-cuts, and designed to operate typically at room temperature (RT), at 5 or $10 \mathrm{MHz}$ on their low-speed (quasi-pure) thickness shear mode, the C-mode. Resonators under test are put inside a pulsetube cryorefrigerator.

\section{QUARTZ RESONATOR BEHAVIOR AT $4 K$}

At helium temperature very low mechanical losses $\phi$ can be achieved [1], i.e. very high quality-factors $Q=1 / \phi$. Ultimate intrinsic losses in the range $[3 \mathrm{~K}-15 \mathrm{~K}]$ and at frequencies greater than a few $\mathrm{MHz}$ in our case are those originating from the interaction of the acoustic wave and phonons according to the Landau-Rumer theory [2]. The latter predict a Q-factor that does not depend on frequency anymore. Q-factors are usually greater than a few millions close to $4 \mathrm{~K}$ and can go beyond a billion on the extensional mode, the A-mode, for high-quality quartz resonators [3].

Moreover, it has been observed from a set of experimental results that the trend of quartz noise, described by its power spectral density of fractional frequency fluctuations $S_{y}(f=$ $1 \mathrm{~Hz}$ ), at the offset frequency $1 \mathrm{~Hz}$, against the unloaded qualityfactor $Q$ can be written as $S_{y}(f=1 \mathrm{~Hz})=1 / Q^{n}$ with $n$ close to 4 [4], [5]. This suggests that flicker noise decreases as Qfactor increases, as expected.

Consequently, high-Q quartz resonators seem like good potential candidates as the heart of ultra-stable cryogenic clocks. Nevertheless a couple of issues regarding the sensitivity of BAW resonators to their environment should be fixed before implementing them inside a cryogenic clock. Indeed, it has been shown that at least temperature first and then vibrations should be minimized [6].
Vibrations of a cryogenerator can be processed to reduce displacements with the machine pulsing period to less than $1 \mu \mathrm{m}$ at the second stage level, where the resonator sits.

Regarding temperature, even if the temperature coefficients are lower at low temperature than at RT, the fractional frequency sensitivity remains typically close to $10^{-9} / K$ because of the non-compensated behavior of the tested modes and cuts, mainly the SC-cut, at cryogenic temperature. The use of a compensated cut is mandatory for implementing an ultra-stable frequency source, i.e. a cut whose frequency-temperature curve has a turning point inside the range [ $3 \mathrm{~K}-15 \mathrm{~K}$ ]. To identify such a cut a campaign has been carried out to measure the temperature sensitivity of the elastic coefficients of quartz within the operating temperature range [7]. In a second step, those results have been used to calculate the temperature coefficients of a selected resonance frequency with respect to cut angles. This calculation has successfully lead to a compensated cut whose frequency-temperature curve is more flat around its turning point than the C-mode of the SC-cut at RT [8].

Thus, all the ingredients would be gathered to consider the design of a cryogenic quartz-based source.

\section{QUARTZ RESONATOR OPERATING AS AN OPTICAL CAVITY}

Quartz is a low mechanical loss material but not the only one: sapphire, diamond, silicon, calcium fluorite... might also be considered [9]. Some of them are non-piezoelectric and an optical excitation could be particularly relevant in that case, which stands true for every material. A light beam incident to a quartz resonator surface can induce an acoustic response by means of various basic processes, or a mix of them, such as Brillouin diffusion, thermal diffusion, radiation pressure, etc. The possible mechanical displacement from the radiation pressure of some incident laser beam results in an extremely weak effect with usual laser power. Nevertheless, one way to magnify efficiently the radiation pressure consists in using the acoustic cavity also as an optical cavity. Indeed, while the acoustic cavity becomes an optical Fabry-Perot, i.e. when proper conditions between the optical length and the cavity thickness are met, multiple round-trips can be described as light trapping between both reflecting surfaces. Accordingly, the displacement 
resulting from a modulated incident laser beam is much bigger than before, as demonstrated in the following section.

Firstly, the tested devices are typically plano-convex resonators whose thickness is $t=0.5 \mathrm{~mm}$ or $1 \mathrm{~mm}$ and radius of curvature in the order of $R \approx 300 \mathrm{~mm}$. Consequently, the condition of stability [10] of the optical cavity, $1-g \geq 0$ with $g=1-t / R$, is close to the boundary of the instability domain but validated anyway.

Secondly, the ability of the optical intracavity field to actuate the mechanical displacement should be checked. The mean intracavity photon flux is $I=\frac{2}{\pi} F I_{\text {laser }}$ where $I_{\text {laser }}$ is the mean incident laser flux and $F$ the cavity finesse, i.e. the amplifying factor. The latter depends on the optical properties of both reflecting surfaces: the usual gold electrodes can be used simply as basic reflectors with a reflectivity of about $96 \%$ at $1550 \mathrm{~nm}$. Thus, the finesse $F$ reaches 80 . Reflectivities could be improved by means of Bragg mirrors for example, and consequently the finesse could be increased, but their impact on mechanical losses should be considered. A trade-off would likely be the solution. The effect of those data on the mechanical displacement is assessed below.

\section{OPTOMECHANICAL COUPLING}

When relating the laser power $P_{\text {laser }}$ to the light intensity $I$, and assuming that both mirrors have the same transmission factor and that optical losses are negligible, it can be shown that the radiation-pressure force from the intracavity beam is:

$$
F_{\text {rad }}=\frac{2 P_{\text {cavity }}}{c_{\text {cavity }}} \approx \frac{2 P_{\text {laser }} F}{\pi c_{\text {cavity }}}
$$

Moreover, the radiation-pressure force induces a mechanical displacement along the axis $y$ normal to the resonator plane (see Fig.1) given by $\delta y(\omega)=\chi_{n}(\omega) \delta F_{\text {rad }}(\omega)$, where $n$ stands for the overtone $n 00$ of the extensional A-mode, and $\chi_{n}$ is the mechanical susceptibility close to the resonance of overtone $n$ at $\omega_{n}$ exhibiting a Q-factor $Q_{n}$. The resulting displacement is then:

$$
\left|\delta y\left(\omega_{n}\right)\right| \approx \frac{4 F}{\pi c_{\text {cavity }}} \frac{Q_{n}}{m_{n} \omega_{n}^{2}}\left|\delta P_{\text {laser }}\right|
$$

where $m_{n}$ is the effective mass. It turns out that the resulting displacement sensitivity would be $1.310^{-10} \mathrm{~m} / \mathrm{mW}$ for a golded quartz resonator with $F=80$. This is compatible with the noise floor which is assessed to $210^{-17} \mathrm{~m} / \sqrt{\mathrm{Hz}}$ for a $1 \mathrm{~mW}$ laser power at $1550 \mathrm{~nm}$ [11].

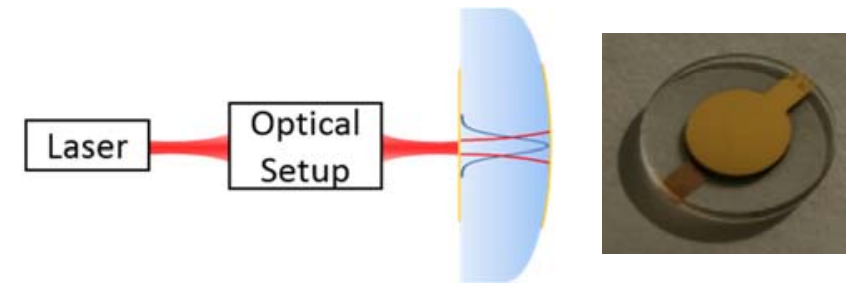

Fig. 1. Optomechanic sketch and typical device.

\section{CONCLUSION}

A typical plano-convex quartz crystal resonator can be used both as an optical and an acoustic cavity, theoretically. The practical proof of concept is in progress.

\section{ACKNOWLEDGMENT}

The authors would like to thank the MENESR France for JB research scholarship, Région Franche-Comté and LabEX FIRST-TF for their funding dedicated to this program, Oscillator IMP platform (EquipEX) for providing reference frequencies.

\section{REFERENCES}

[1] S. Galliou, J. Imbaud, M. Goryachev, R. Bourquin, Philippe Abbé, Losses in high quality quartz crystal resonators at cryogenic temperatures, Appl. Phys. Lett. 98, 091911, 2011.

[2] L. Landau and G. Rumer, Phys. Z. Sowjetunion 11, 18, 1937.

[3] S. Galliou, M. Goryachev, R. Bourquin, Ph. Abbé, J. P. Aubry, and M. E. Tobar, Extremely Low Loss Phonon-Trapping Cryogenic Acoustic Cavities for Future Physical Experiments, Scientific Reports, 3, 2132, 2013.

[4] J.J. Gagnepain, J. Ubersfeld, G.Goujon, P. Handel, Relationship Between $1 / f$ Noise and Q-factor in Quartz Resonators at Room and Low Temperatures, First Theoritical Interpretation, Proc. 35th Ann. Frequency Control Symp., 1981, pp. 476-483.

[5] F. L. Walls, P. H. Handel, R. Besson, and J. J. Gagnepain, A New Model of $1 / \mathrm{f}$ Noise in BAW Quartz Resonators, Proc. of IEEE Frequency Control Symp., 1992, pp. 327-333.

[6] M. Goryachev, S. Galliou, Ph. Abbé, P.-Y. Bourgeois, S. Grop, B. Dubois, Quartz Resonator Instabilities Under Cryogenic Conditions, IEEE Trans. on UFFC, vol. 59, No. 1, pp. 21-29, 2012.

[7] J. Bon, S. Galliou, R. Bourquin, Temperature coefficients of crystallinequartz elastic constants over the cryogenic range [4 K, $15 \mathrm{~K}$ ], Appl. Phys. Lett., 109, 231902, 2016.

[8] J. Bon, S. Galliou, R. Bourquin, Compensated cut of crystalline-quartz over the cryogenic range $[4 \mathrm{~K}, 15 \mathrm{~K}]$. To be published.

[9] R. Nawrodt, L. Cunningham, R. Flaminioz, J. Francy, D. Heinertz, J. Hough, I. Martin, N. Morgadoy, S. Rowan, C. Schwarzz, P. Seidelz, Mirror thermal noise calculation for ET, European Commission FP7, Grant Agreement 211743, 18 pages, August 10, 2009.

[10] Paper describing stability/instability of optical cavity.

[11] Cryogenic quartz optomechanical cavity, J. Bon, L. Neuhaus, S. Deléglise, T. Briant, Ph. Abbé, P.-F. Cohadon, and S. Galliou, in preparation. 